\title{
Dyslipidemia and Fasting Glucose Impairment among HIV-Infected Patients 48-Weeks after the First Antiretroviral Regimen
}

José Antonio Mata-Marín ${ }^{1 \#}$, Bulmaro Manjarrez-Téllez"1", Jesús Gaytán-Martínez', Marcelino Chávez-García ${ }^{2 \#}$, Marco Isaac Banda-Lara ${ }^{3}$,

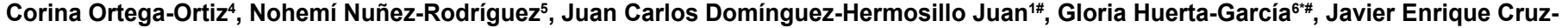
Herrera ${ }^{7}$, Rocío Zapata-López ${ }^{4}$ and Jorge Sandoval-Ramírez ${ }^{1 \#}$

${ }^{1}$ Infectious Diseases Department, Hospital de Infectología, Centro Médico Nacional "La Raza", IMSS. México City, Mexico

${ }^{2}$ Unidad Médica de Alta Especialidad No. 25, IMSS, Monterrey, Nuevo León. México

${ }^{3}$ HGR San Luis Potosí, IMSS, SLP, México

${ }^{4}$ UAM, Campus Xochimilco, Mexico City, Mexico

${ }^{5}$ CLISIDA, HGZ 48, IMSS, Mexico City, Mexico

${ }^{6}$ Departamento de Infectología Pediátrica. Unidad Médica de Alta Especialidad, Hospital de Pediatría, Centro Médico Nacional "Siglo XXI", IMSS. Mexico City, México ${ }^{7}$ CLISIDA, HGZ-No.72, IMSS, Mexico City, México

\#These authors have contributed equally to the work

\section{Abstract}

Background: People infected with human immunodeficiency virus (HIV) develop lipid and glucose metabolic alterations, which predisposes them to cardiovascular disease. The aim of this study was to evaluate the cumulative incidence of dyslipidemia and fasting glucose impairment after 48 weeks of initiating the first antiretroviral (ART) regimen and the association with the type of ART regimen.

Method: Retrospective cohort of HIV-1 infected patients attending in the AIDS clinic of five centers of the country, between February 2009 and March 2013. Lipids (total cholesterol and triglycerides) and fasting glucose, were collected prior and 48 weeks after starting ART. We assessed risk factors for dyslipidemia and fasting glucose. To adjust for the effects of potential confounders of metabolic alterations we used logistic regression model.

Results: During the study, 223 patients on ART were evaluated. Median age was 34 years [interquartile range (IQR): 28-43]. Of the total patients, $201(90 \%)$ were men. Most common OBR regimens were tenofovir/emtricitabine (TDF/FTC), and efavirenz (EFV) in 42\%, abacavir/lamivudine (ABC/3TC) +EFV in 16.6\% and TDF/FTC+nevirapine (NVP) in $11.7 \%$ patients. Cumulative incidence per 1,000 patients/year of glucose $\geq 100 \mathrm{mg} / \mathrm{dL}$ was 233.1 , total cholesterol $>200 \mathrm{mg} / \mathrm{dL}$ was 273.5 and tryglicerides $>200 \mathrm{mg} / \mathrm{dL}$ was 372.2 .

The proportion of patients with hypertriglyceridemia (>200 mg/dL) at 48 weeks of ART initiation was $37.2 \%(95 \%$ Cl: 31.1-43.7\%), hypercholesterolemia (>200 mg/dL) 32.3\% (95\% Cl: $26.5-38.6 \%$ ) and impairment of fasting glucose (IFG) (>100 mg/dL) 23.3\% (95\% Cl: 18.2-29.2\%), After adjustment in a logistic regression model for IFG, EFV-containing regimen OR $2.9(95 \% \mathrm{Cl} 1.12-7.45)$; $p=0.027$; for hypertriglyceridemia, age $>40$ years old $\mathrm{OR}=1.9(95 \% \mathrm{Cl}: 1.01-3.63)$; $\mathrm{p}=0.044, \mathrm{ABC} / \mathrm{LAM}$-containing regimen $\mathrm{OR}=2.69$ (95\% Cl: 1.42-5.09); $\mathrm{p}=0.002$ and $\mathrm{LPV} / \mathrm{r}$-containing regimen $\mathrm{OR}=5.04$ $(95 \% \mathrm{Cl} 2.32-10.92) ; \mathrm{p}=0.001$ were significant; finally, for hypercholesterolemia age $>40$ years old $\mathrm{OR}=2.4(95 \% \mathrm{Cl}: 1.15-$ 4.9); $p=0.004$ and $A B C / 3 T C$-containing regimen $O R=1.87$ (95\% Cl: 1.01-3.49); $p=0.05$ remain significant.

Conclusion: These data show high risk of cumulative incidence of IFG and dyslipidemia after initiation of ART. Age $>40$ years old, ABC/3TC and LPV/r-containing regimens were independent factors to develop dyslipidemia and EFV-containing regimen for IFG in this cohort.

Keywords: Dyslipidemia; Impaired fasting glucose; Antiretroviral therapy; HIV

\section{Background}

With the increased survival of HIV-infected patients, there have emerged a number of unexpected consequences of chronic illness and drugs adverse events, especially in the form of metabolic disease [1].

Available data suggest the presence of an accelerated process of coronary atherosclerosis in this population due to multiple factors, including a higher prevalence (compared with non-HIV-infected patients) of conventional risk factors, emerging risk factors (chronic inflammation, immune activation, and senescence related to HIV infection itself), and the role of antiretroviral therapy (ART), regarding metabolic syndrome as one of the major problems [2]. Some studies have showed that the prevalence of metabolic syndrome was higher among HIV-infected patients on ART than among non-HIV-infected healthy controls (15.8 vs. 3.2\%) [3]. A high incidence of diabetes mellitus (DM) and impaired fasting glucose (IFG) has been detected in HIV-infected patients receiving ART $[4,5]$. Another studies have found relationship between some classes of antiretroviral (ARV) drugs such as protease inhibitors (PIs) and nucleos $(\mathrm{t})$ ide retrotranscriptase inhibitors (NRTIs) with a higher frequency of new-onset DM and IFG [6].

Dyslipidemia is particularly frequent and is mostly characterized by hypertriglyceridemia and low HDL-cholesterol concentrations.

*Corresponding author: Gloria Huerta García, Servicio de Infectología, Hospital de Pediatría Centro Médico Nacional Siglo XXI, Avenida Cuauhtémoc 330, Cuauhtémoc, Doctores, 06720 Ciudad de México, Tel: + 52-56276900; E-mail: gloriahuerta@gmail.com

Received November 25, 2015; Accepted December 28, 2015; Published December 31, 2015

Citation: Mata-Marín JA, Manjarrez-Téllez B, Gaytán-Martínez J, Chávez-García M Banda-Lara Ml, et al. (2015) Dyslipidemia and Fasting Glucose Impairment among HIV-Infected Patients 48-Weeks after the First Antiretroviral Regimen. J AIDS Clin Res 6: 533. doi:10.4172/2155-6113.1000533

Copyright: (C) 2015 Mata-Marín JA, et al. This is an open-access article distributed under the terms of the Creative Commons Attribution License, which permits unrestricted use, distribution, and reproduction in any medium, provided the original author and source are credited. 
Citation: Mata-Marín JA, Manjarrez-Téllez B, Gaytán-Martínez J, Chávez-García M, Banda-Lara MI, et al. (2015) Dyslipidemia and Fasting Glucose Impairment among HIV-Infected Patients 48-Weeks after the First Antiretroviral Regimen. J AIDS Clin Res 6: 533. doi:10.4172/21556113.1000533

Page 2 of 4

Although this is observed in treatment-naive HIV-infected patients, suggesting that HIV infection itself has a metabolically deleterious effect, this phenomenon has been attributed, principally, to the use of PIs (i.e., ritonavir- boosted treatments), and some NRTIs (i.e., zidovudine or abacavir) $[7,8]$.

Dyslipidemia is a significant risk factor for cardiovascular disease. People infected with HIV have alterations in lipids and glucose metabolism, which predisposes to cardiovascular disease. ART may contribute to these changes.

The objective of this study was to evaluate the cumulative incidence of dyslipidemia and IFG 48 weeks after initiating an antiretroviral regimen, and the association with the type of antiretroviral used in a cohort of naïve HIV-infected patients.

\section{Method}

\section{Design}

We conducted a retrospective cohort from 1 June 2014 to 30 December 2014 of HIV-1 treatment naïve-infected adults who started therapy for the first time. Dyslipidemia (total cholesterol and triglycerides) and fasting plasma glucose, before and 48 weeks after starting ART were collected.

\section{Patients}

The hospital institutional review board and ethics committee reviewed and approved this study (reference number R-2015-3502-70).

Patients who had indication for HIV treatment, were recruited from 4 referral centers in 4 different States of Mexico. Patients were $>16$ years of age with confirmed HIV-1 infection by Enzyme-Linked ImmunoSorbent Assay and Western blot. Patients had baseline levels of glucose $<100 \mathrm{mg} / \mathrm{dL}$, tryglicerides (TG) and total cholesterol (TC) $<200 \mathrm{mg} / \mathrm{dL}$. They were stratified according to age $\geq 40$ years old. The ARV regimen started was selected according to the availability in the HIV clinics and to the decision of the treating physician; the backbone was abacavir/lamivudine (ABC/3TC) or tenofovir/emtricitabine (TDF/ FTC), and the third drug was among efavirenz (EFV), nevirapine (NVP), atazanavir/ritonavir (ATV/r) or lopinavir/ritonavir (LPV/r).

Exclusion criteria were baseline values of alanine or aspartate aminotransferase $\geq 200 \mathrm{mg} / \mathrm{dL}$ (5 times the upper normal limit), creatinine $\geq 2.6 \mathrm{mg} / \mathrm{dL}$ (2 times the upper normal limit), IFG $\geq 100 \mathrm{mg}$ / $\mathrm{dL}, \mathrm{DM}$ or by the use of anti-diabetic agents, obesity defined as a body mass index $\geq 30 \mathrm{~kg} / \mathrm{m}^{2}$, TC or TG $\geq 200 \mathrm{mg} / \mathrm{dL}$, use of drugs known to affect lipid or glucose metabolism within 1 month prior to inclusion, any AIDS-defining event requiring parenteral therapy, change of a drug in the regimen, patient on virological failure, and pregnancy or lactation at the inclusion or during the first 48 weeks of study. Patients with missing data were not included in the cohort.

\section{Measurements}

Clinical history regarding CD4+ cells count, HIV-1 RNA viral load, and serum laboratory parameters were recorded at each site at the beginning of the therapy and after 48 weeks, with similar methods of performance. Fasting plasma glucose, TG and TC were collected and measured using commercial enzymatic kits. We were not able to measure HDL in all of our HIV clinics; therefore, we excluded it in the analysis. Newonset diabetes was defined if fasting plasma glucose $>126$ $\mathrm{mg} / \mathrm{dL}$ was measured on two consecutive occasions, fasting glucose impairment if fasting plasma glucose $\geq 100 \mathrm{mg} / \mathrm{dL}$ was measured on two consecutive occasions. Finally, hy- percholesterolemia and dyslipidemia were defined as total cholesterol $200 \mathrm{mg} / \mathrm{dL}$ or greater, tryglierides $200 \mathrm{mg} / \mathrm{dL}$ or greater, or receiving cholesterol-lowering medication.

\section{Statistical analysis}

Baseline characteristics were summarized using medians and interquartile ranges (IQR) for continuous variables, and proportions for categorical variables. Descriptive statistics were used to evaluate changes in TG, TC, CD4+ cells count and HIV-1 RNA viral load from baseline. For categorical variables, number of values in each category and percentage of the values with regard of the number of patients in the study population were calculated. Explorative statistical methods were used considering the efficacy endpoints and changes in safetyrelevant laboratory parameters. Significance changes from baseline of TC and TG were tested using the Wilcoxon signed-rank test.

Cumulative incidence was calculated with number of events per 1,000 people/years.

For those patients with hypertriglyceridemia and hypercholesterolemia, we analyzed the potential causes, including the antiretroviral regimen in a bivariate analysis, which included crude odds ratios (OR) by Fisher's exact test and Chi-squared. Independent risk factors associated with hypertriglyceridemia and hypercholesterolemia at week 24 and 48 were identified in the multivariate logistic regression analysis that included variables from bivariate analysis with a $P$ value $\leq 0.1$. All analyses were performed using SPSS software (Version 19.0. Armonk, NY: IBM Corp.).

\section{Results}

During the study, 223 patients on ART were evaluated. Median age was 34 years (IQR: $28-43$ ); $34.1 \%$ of patients (76) were $\geq 40$ years old. Of the total patients, $201(90.1 \%)$ were men. Median baseline glucose was $88 \mathrm{mg} / \mathrm{dL}$ (IQR 82-94), TC $145 \mathrm{mg} / \mathrm{dL}$ (IQR 119-167) and TG $133 \mathrm{mg} /$ dL (IQR 101-159) (Table 1).

\begin{tabular}{|c|c|}
\hline Characteristic & Value $^{a}$ \\
\hline Male, n (\%) & $201(90.1 \%)$ \\
\hline Age, years & $34(28-43)$ \\
\hline Age $\geq 40$ years & $76(34.1 \%)$ \\
\hline $\mathrm{BMI}^{\mathrm{b}}\left(\mathrm{kg} / \mathrm{m}^{2}\right)$ & $23(21-25)$ \\
\hline Baseline CD4 ${ }^{+}$cell count (cells $/ \mu \mathrm{L}$ ) & $209(92-316)$ \\
\hline Baseline $\mathrm{CD}^{+}{ }^{+}$cell count $<200$ cells $/ \mu \mathrm{L}, \mathrm{n}(\%)$ & $107(48.0 \%)$ \\
\hline Baseline HIV-1 RNA viral load, $\log _{10}$ copies $/ \mathrm{mL}$ & $4.97(4.54-5.42)$ \\
\hline Baseline HIV-1 RNA viral load >100,000 copies/mL, n (\%) & $108(48.4 \%)$ \\
\hline TDF/FTC ${ }^{\circ}$ in regimen, $\mathrm{n}(\%)$ & $109(66.5 \%)$ \\
\hline 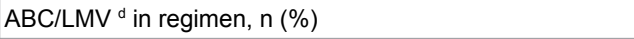 & $71(31.8 \%)$ \\
\hline EFV ${ }^{e}$ in regimen, $n(\%)$ & $131(58.7 \%)$ \\
\hline NVP ${ }^{f}$ in regimen, $\mathrm{n}(\%)$ & $36(16.1 \%)$ \\
\hline $\mathrm{LPV} / \mathrm{r}^{\mathrm{g}}$ in regimen, $\mathrm{n}(\%)$ & $45(20.2 \%)$ \\
\hline ATV $/ \mathrm{r}^{\mathrm{h}}$ in regimen, $\mathrm{n}(\%)$ & $11(4.9 \%)$ \\
\hline Glucose (mg/dL) & $88(82-94)$ \\
\hline $\mathrm{TC}^{\mathrm{i}}(\mathrm{mg} / \mathrm{dL})$ & $145(119-167)$ \\
\hline $\mathrm{TG}^{\mathrm{j}}(\mathrm{mg} / \mathrm{dL})$ & $133(101-159)$ \\
\hline
\end{tabular}

a Values are presented as number (percentage) or as median (IQR). b BMI: Body mass index. c TDF/FTC: Tenofovir/emtricitabina.

d ABC/3TC: Abacavir/lamivudina. e EFV: Efavirenz, f NVP: Nevirapine, g LPV/r: Lopinavir/ritonavir, h ATV/r: Atazanavir/ritonavir, i TC: Total cholesterol, j TG: Trygliderides 
Citation: Mata-Marín JA, Manjarrez-Téllez B, Gaytán-Martínez J, Chávez-García M, Banda-Lara MI, et al. (2015) Dyslipidemia and Fasting Glucose Impairment among HIV-Infected Patients 48-Weeks after the First Antiretroviral Regimen. J AIDS Clin Res 6: 533. doi:10.4172/21556113.1000533

Page 3 of 4

\section{Characteristic}

Glucose $\geq 126 \mathrm{mg} / \mathrm{dL}^{*}$ (type $2 \mathrm{DM}$ )

Glucose $\geq 100 \mathrm{mg} / \mathrm{dL}$ (IFG)

Total cholesterol $\geq 200 \mathrm{mg} / \mathrm{dL}$

Triglycerides $\geq 200 \mathrm{mg} / \mathrm{dL}$
No. of patients (\%)

$3(1.3 \%)$

$52(23.3 \%)$

$61(27.4 \%)$

$83(37.2 \%)$
Incidence ${ }^{* *}$

$3 / 223=13.4$

$52 / 223=233.1$

$61 / 223=273.5$

$83 / 223=372.2$

* Glucose $>126 \mathrm{md} / \mathrm{dL}$ on two occasions

** per 1000 person/years

Table 2: Cumulative incidence of metabolic alterations 48 weeks after initiation of art.

Baseline CD4+ cells count was 209 cells/ $\mu \mathrm{L}$ (IQR 92-316), 107 patients (48\%) had CD4+ cells count $<200$ cells/ $\mu \mathrm{L}$; median RNA HIV1 viral load was 94.700 copies/mL (IQR 35,435-266,520), 108 (48\%) started with $\mathrm{VL}>100,000$ copies $/ \mathrm{mL}$

Most common regimens were TDF/FTC+EFV in $42 \%$ patients, $\mathrm{ABC} / 3 \mathrm{TC}+\mathrm{EFV}$ in $16.6 \%$ patients and $\mathrm{TDF} / \mathrm{FTC}+\mathrm{NVP}$ in $11.7 \%$ patients. The two PIs included were LPV/r and ATV/r (Table 1).

After 48 weeks of treatment, DM2 was found in 3 patients (1.3\%), IFG ( $\geq 100 \mathrm{mg} / \mathrm{dL})$ in 52 patients $(23.3 \%)$, hypercholesterolemia $(\geq 200$ $\mathrm{mg} / \mathrm{dL})$ in 72 patients $(32.3 \%)$ and hypertriglyceridemia $(\geq 200 \mathrm{mg} / \mathrm{dL})$ in 83 patients $(37.2 \%)$ (Table 2$)$.
Regarding the antiretroviral regimen, cumulative incidence of IFG was associated with $\mathrm{ABC} / 3 \mathrm{TC}+\mathrm{EFV}$ in 324.3 per 1000 people/year; cumulative incidence of hypercholesterolemia was associated with TDF/ FTC+LPV/r in 619.0 per 1000 people/year; finally, higher cumulative incidence of hypertriglyceridemia was found with $\mathrm{ABC} / 3 \mathrm{TC}+\mathrm{LPV} / \mathrm{r}$ in 791.6 per 1000 people/year (Table 3).

After adjustment in a logistic regression model for IFG, EFVcontaining regimen OR 2.90 (95\% CI 1.12-7.45); $\mathrm{p}=0.027$, for hypertriglyceridemia, age 40 years old 1.9 (95\% CI: 1.01-3.63); $\mathrm{p}=0.044$, $\mathrm{ABC} / 3 \mathrm{TC}$-containing regimen $\mathrm{OR}=2.69$ (95\% CI: 1.42-5.09); $\mathrm{p}=0.002$ and $\mathrm{LPV} / \mathrm{r}$-containing regimen $\mathrm{OR}=5.04$ (95\% CI 2.32-10.92); $\mathrm{p}=0.001$ were significant,and for hypercholesterolemia age $\geq 40$ years old 2.4 (95\% CI: 1.15-4.9); $\mathrm{p}=0.004$, and $\mathrm{ABC} / 3 \mathrm{TC}-$ containing regimen $\mathrm{OR}=1.87$ (95\% CI: 1.01-3.49); $\mathrm{p}=0.05$ remain significant (Table 4).

\section{Discussion}

In this study, a high frequency of metabolic alterations after one year of antiretroviral treatment was found. The most frequent alteration was hypertriglyceridemia (37.2\%), followed by hypercholesterolemia (27.4), IFG (23.3\%), and finally 3 patients (1.3\%) developed DM2 during the study period. Regarding the antiretroviral regimen, the

\begin{tabular}{|c|c|c|c|c|c|c|c|c|}
\hline Regimen & $T D F / F T C+E F V$ & $T D F / F T C+N V P$ & $A B C / 3 T C+L P V / r$ & $A B C / 3 T C+E F V$ & $A B C / 3 T C+N V P$ & $T D F / F T C+L P V / r$ & $T D F / F T C+A T V / r$ & $p$ value \\
\hline Glucose $\geq 126 \mathrm{mg} / \mathrm{dL}^{*}$ (type $2 \mathrm{DM}$ ) & 10.6 & 38.4 & 41.6 & 0 & 0 & 0 & 0 & 0.704 \\
\hline Glucose $\geq 100$ mg/dL (IFG) & 180.8 & 230.7 & 83.3 & 324.3 & 100 & 95.2 & 90.9 & 0.170 \\
\hline $\mathrm{TC} \geq 200 \mathrm{mg} / \mathrm{dL}$ & 212.7 & 153.8 & 416.6 & 513.5 & 200 & 619.0 & 571.4 & 0.001 \\
\hline $\mathrm{TG} \geq 200 \mathrm{mg} / \mathrm{dL}$ & 255.3 & 115.3 & 791.6 & 459.4 & 400 & 666.6 & 181.8 & 0.001 \\
\hline
\end{tabular}

Table 3: Cumulative incidence of metabolic alterations by regimen at 48 weeks.

4a. Bivariate and multivariate analysis of risk factors associated with IFG

\begin{tabular}{|c|c|c|c|c|c|c|}
\hline \multicolumn{7}{|c|}{ 4a. Bivariate and multivariate analysis of risk factors associated with IFG. } \\
\hline \multicolumn{4}{|c|}{ Bivariate } & \multicolumn{2}{|c|}{ Multivariate } & \multirow[b]{2}{*}{$\mathrm{p}$ value } \\
\hline Risk factor & OR unadjusted & $95 \% \mathrm{Cl}$ & $\mathrm{p}$ value & OR adjusted & $95 \% \mathrm{Cl}$ & \\
\hline Male gender & 0.742 & $(0.25-2.14)$ & 0.580 & & & \\
\hline Age $\geq 40$ years & 2.143 & $(1.07-4.26)$ & 0.028 & 1.81 & $(0.92-3.55)$ & 0.083 \\
\hline Baseline HIV-1 RNA $\geq 100,000$ copies/mL & 1.057 & $(0.53-2.09)$ & 0.874 & & & \\
\hline Baseline $\mathrm{CD}^{+}{ }^{+}$cells count $<200$ cells $/ \mu \mathrm{L}$ & 0.671 & $(0.33-1.32)$ & 0.250 & & & \\
\hline ABC/LMV-containing regimen ${ }^{a}$ & 1.298 & $(0.63-2.63)$ & 0.470 & & & \\
\hline LPV/r-containing regimen ${ }^{b}$ & 0.372 & $(0.12-3.09)$ & 0.066 & 1.50 & $(0.47-4.70)$ & 0.487 \\
\hline EFV-containing regimen ${ }^{c}$ & 1.938 & $(0.93-4.03)$ & 0.074 & 2.90 & $(1.12-7.45)$ & 0.027 \\
\hline \multicolumn{7}{|c|}{ 4b. Bivariate and multivariate analysis of risk factors associated with hypercholesterolemia. } \\
\hline Risk factor & OR unadjusted & $95 \% \mathrm{Cl}$ & $\mathrm{p}$ value & OR adjusted & $95 \% \mathrm{Cl}$ & $\mathrm{p}$ value \\
\hline Male gender & 1.02 & $(0.39-2.63)$ & 0.960 & & & \\
\hline Age $\geq 40$ years & 2.77 & $(1.54-4.98)$ & 0.001 & 2.462 & $(1.33-4.54)$ & 0.004 \\
\hline Baseline HIV-1 RNA $\geq 100,000$ copies/mL & 0.799 & $(0.45-1.40)$ & 0.437 & & & \\
\hline Baseline $\mathrm{CD}^{+}{ }^{+}$cells count $<200$ cells $/ \mu \mathrm{L}$ & 1.34 & $(0.76-2.35)$ & 0.309 & & & \\
\hline ABC/LMV-containing regimen ${ }^{a}$ & 2.09 & $(1.16-3.78)$ & 0.013 & 1.870 & $(1.01-3.49)$ & 0.05 \\
\hline LPV/r-containing regimen ${ }^{b}$ & 2.75 & $(1.40-5.38)$ & 0.003 & 2.411 & $(0.94-6.16)$ & 0.066 \\
\hline EFV-containing regimen ${ }^{c}$ & 0.717 & $(0.40-1.26)$ & 0.248 & & & \\
\hline \multicolumn{7}{|c|}{ 4c. Bivariate and multivariate analysis of risk factors associated with hypertrigliceridemia. } \\
\hline Risk factor & OR unadjusted & $95 \% \mathrm{Cl}$ & $\mathrm{p}$ value & OR adjusted & $95 \% \mathrm{Cl}$ & $p$ value \\
\hline Male gender & 0.684 & $(0.28-1.66)$ & 0.400 & & & \\
\hline Age $\geq 40$ years & 2.467 & $(1.39-4.37)$ & 0.002 & 1.924 & $(1.01-3.63)$ & 0.044 \\
\hline Baseline HIV-1 RNA $\geq 100,000$ copies/mL & 0.944 & $(0.57-1.71)$ & 0.984 & & & \\
\hline Baseline $\mathrm{CD} 4^{+}$cells count $<200$ cells $/ \mu \mathrm{L}$ & 0.725 & $(0.42-1.25)$ & 0.247 & & & \\
\hline ABC/LMV-containing regimen ${ }^{a}$ & 3.271 & $(1.81-5.88)$ & 0.001 & 2.695 & $(1.42-5.09)$ & 0.002 \\
\hline LPV/r-containing regimen ${ }^{\mathrm{b}}$ & 7.040 & $(3.36-14.71)$ & 0.001 & 5.044 & $(2.32-10.92)$ & 0.001 \\
\hline EFV-containing regimen ${ }^{c}$ & 0.559 & $(0.32-0.97)$ & 0.038 & 1.972 & $(0.85-4.55)$ & 0.112 \\
\hline
\end{tabular}

a ABC/3TC: Abacavir/Lamivudina, b LPV/r: Lopinavir/Ritonavir, c EFV: Efavirenz,

Table 4: Bivariate and multivariate analysis of risk factors associated with IFG and dyslipidemia. 
Citation: Mata-Marín JA, Manjarrez-Téllez B, Gaytán-Martínez J, Chávez-García M, Banda-Lara MI, et al. (2015) Dyslipidemia and Fasting Glucose Impairment among HIV-Infected Patients 48-Weeks after the First Antiretroviral Regimen. J AIDS Clin Res 6: 533. doi:10.4172/21556113.1000533

Page 4 of 4

highest cumulative incidence of dyslipidemia was associated with $\mathrm{ABC} / 3 \mathrm{TC}$ and $\mathrm{LPV} / \mathrm{r}$ containing regimens.

Some independent risk factors were found to be associated with metabolic alterations; regarding IFG, EFV-containing regimens was the only factor that remained significant; other studies have associated EFV as an independent risk factor for increase glucose $[9,10]$.

Some factors were common risk factors for dyslipidemia, such as age $\geq 40$ years; in other studies, metabolic alterations has been found to be associated with older age, and in patients over 40 years old a higher rate of dyslipidemia, diabetes and metabolic syndrome has been described $[11,12]$.

Our data is similar to those of Desfaye, who found that more than $25 \%$ of patients developed dyslipidemia; in addition, an increase in lipids and glucose levels was reported after starting ART [13].

These findings are similar to those reported by Pinto Neto, who found $22.3 \%$ of dyslipidemia after 3 years of treatment; in this study, $\mathrm{LPV} / \mathrm{r}$ was reported as an associated risk factor [14]. Another study, ACTG5142, showed a high increase in TC and TG associated with $\mathrm{LPV} / \mathrm{r}$, similar to ours observed in this cohort [15].

In this cohort, one of the independent risk factor associated with dyslipidemia was $\mathrm{ABC} / 3 \mathrm{TC}$-containing regimen confirming previous reported results. The association of $\mathrm{ABC}$ with dyslipidemia has been reported in some studies; in the HEAT trial, $\mathrm{ABC} / 3 \mathrm{TC}$ was associated with an increase in TC and TG at 96 weeks; however, glucose had no modification related to this backbone [16]. Another study, ACTG5202, found a higher frequency of dyslipidemia with $\mathrm{ABC} / 3 \mathrm{TC}$ either with ATV/r or with EFV [17]. Finally, the ASSERT trial, found a statistically significant increase in TC and TG with $\mathrm{ABC} / \mathrm{LMV}$ regimens compared with TDF/FTC in treatment-naïve infected patients [18].

The present study has some limitations; it includes a retrospective method, few numbers of patients in some groups such as ATV/r and the absence of patients with RAL-containing regimens due to it is not approved for initial therapy in our country. Another limitation is that we did not have the possibility to measure HDL and LDL in our HIV Clinics; these lipoproteins have a strong correlation with cardiovascular risk. Finally because the retrospective method, we were not able to evaluate lifestyle and its impact on lipid levels.

On the other hand, this is the first study developed in Mexico, which analyzed lipids and glucose levels after the first year of ART in treatmentnaive infected patients. These results allow us to have a panoramic vision about how many patients might develop dyslipidemia and that will require interventions, concerning modifications in lifestyle and the use of drugs that decrease lipids, such as statins and hypoglycemic drugs for example metformin; in addition, we confirmed that $\mathrm{ABC} / 3 \mathrm{TC}$ and $\mathrm{LPV} / \mathrm{r}$ are drugs associated with dyslipidemia in this population.

It is necessary to conduct a prospective cohort study including a higher number of patients to confirm these findings being representative of our country.

\section{Conclusion}

In conclusion, in Mexico there is a high incidence of metabolic alterations in HIV infected patients during the first year of ART initiation, even if they are young patients, especially when their ART regimen contains $\mathrm{ABC} / \mathrm{LMV}$ and/or $\mathrm{LPV} / \mathrm{r}$.

\section{Acknowledgement}

The authors wish to thank all the centers and investigators who participated in this study.

\section{Funding}

The project was supported by the authors.

\section{References}

1. Hadigan C, Meigs JB, Corcoran C, Rietschel P, Piecuch S, et al. (2001) Metabolic abnormalities and cardiovascular disease risk factors in adults with human immunodeficiency virus infection and lipodystrophy. Clin Infect Dis 32: 130-139.

2. Grinspoon SK (2005) Metabolic syndrome and cardiovascular disease in patients with human immunodeficiency virus. Am J Med 118 Suppl 2: 23S-28S.

3. Estrada V, Martínez-Larrad MT, González-Sánchez JL, de Villar NG, Zabena C, et al. (2006) Lipodystrophy and metabolic syndrome in HIV-infected patients treated with antiretroviral therapy. Metabolism 55: 940-945.

4. Zhang C, Chow FC, Han Y, Xie J, Qiu Z, et al. (2015) Multicenter cohort study of diabetes mellitus and impaired fasting glucose in HIV-infected patients in China. J Acquir Immune Defic Syndr 68: 298-303.

5. De Wit S, Sabin CA, Weber R, Worm SW, Reiss P, et al. (2008) Incidence and risk factors for new-onset diabetes in HIV-infected patients: the Data Collection on Adverse Events of Anti-HIV Drugs (D:A:D) study. Diabetes Care 31: 12241229.

6. Capeau J, Bouteloup V, Katlama C, Bastard JP, Guiyedi V, et al, (2012) Tenyear diabetes incidence in 1046 HIV-infected patients started on a combination antiretroviral treatment. AIDS 26: 303-314.

7. Fisher SD, Miller TL, Lipshultz SE (2006) Impact of HIV and highly active antiretroviral therapy on leukocyte adhesion molecules, arterial inflammation, dyslipidemia, and atherosclerosis. Atherosclerosis 185: 1-11.

8. Umpleby AM, Das S, Stolinski M, Shojaee-Moradie F, Jackson NC, et al. (2005) Low density lipoprotein apolipoprotein B metabolism in treatment-naive HIV patients and patients on antiretroviral therapy. Antivir Ther 10: 663-670.

9. Dave JA, Lambert EV, Badri M, West S, Maartens G, et al. (2011) Effect of nonnucleoside reverse transcriptase inhibitor-based antiretroviral therapy on dysglycemia and insulin sensitivity in South African HIV-infected patients. J Acquir Immune Defic Syndr 57: 284-289.

10. Manuthu EM, Joshi MD, Lule GN, Karari E (2008) Prevalence of dyslipidemia and dysglycaemia in HIV infected patients. East Afr Med J 85: 10-17.

11. Ryan R, Dayaram YK, Schaible D, Coate B, Anderson D1 (2013) Outcomes in older versus younger patients over 96 weeks in HIV-1- infected patients treated with rilpivirine or efavirenz in ECHO and THRIVE. Curr HIV Res 11: 570-575.

12. Albuquerque VM, Zírpoli JC, de Barros Miranda-Filho D, Albuquerque Mde F, Montarroyos UR, et al. (2013) Risk factors for subclinical atherosclerosis in HIV-infected patients under and over 40 years: a case-control study. BMC Infect Dis 13: 274

13. Tesfaye DY, Kinde S, Medhin G, Megerssa YC, Tadewos A, et al. (2014) Burden of metabolic syndrome among HIV-infected patients in Southern Ethiopia. Diabetes Metab Syndr 8: 102-107.

14. Pinto Neto LF, das Neves MB, Ribeiro-Rodrigues $R$, Page $K$, Miranda AE (2013) Dyslipidemia and fasting glucose impairment among HIV patients three years after the first antiretroviral regimen in a Brazilian AIDS outpatient clinic. Braz J Infect Dis 17: 438-443.

15. Riddler SA, Haubrich R, DiRienzo AG, Peeples L, Powderly WG, et al. (2008) Class-sparing regimens for initial treatment of HIV-1 infection. $\mathrm{N}$ Engl $\mathrm{J}$ Med 358: 2095-2106.

16. Smith KY, Patel P, Fine D, Bellos N, Sloan L, et al. (2009) Randomized, doubleblind, placebo-matched, multicenter trial of abacavir/lamivudine or tenofovir/ emtricitabine with lopinavir/ritonavir for initial HIV treatment. AIDS 23: 1547 1556.

17. Smith KY, Tierney C, Mollan K, Venuto CS, Budhathoki C, et al. (2014) Outcomes by sex following treatment initiation with atazanavir plus ritonavir or efavirenz with abacavir/lamivudine or tenofovir/emtricitabine. Clin Infect Dis 58: 555-563.

18. Moyle GJ, Stellbrink HJ, Compston J, Orkin C, Arribas JR, et al. (2013) 96Week results of abacavir/lamivudine versus tenofovir/emtricitabine, plus efavirenz, in antiretroviral-naive, HIV-1-infected adults: ASSERT study. Antivir Ther 18: 905-913. 